\title{
Efeito do Compatibilizante SBS e da Granulometria nas Propriedades Mecânicas de Blendas de PS/Resíduo de Borracha (SBRr)
}

\section{Effect of SBS Compatibilizer SBS and Particle size on Mechanical Properties of Blends of PS/Waste Rubber (SBRr)}

\author{
Carlos Bruno Barreto Luna'; Divânia Ferreira da Silva²; Sabrina Kelly Trajano Basílio; \\ Edcleide Maria Araújo ${ }^{4}$
}

Resumo

Uma forma de modificar as propriedades de sistemas poliméricos é a mistura física de mais de um polímero, ou seja, as blendas poliméricas. Pretende-se com este trabalho produzir blendas poliméricas a partir de uma matriz de poliestireno com resíduos de borracha, visando estudar o efeito da granulometria e do compatibilizante nas propriedades mecânicas de impacto e tração. As blendas de poliestireno/ resíduos de borracha, inicialmente foram preparadas em uma extrusora de rosca dupla corrotacional e, posteriormente, os grânulos extrusados foram moldados por injeção. Ficou evidenciado que $5 \%$ em peso do compatibilizante SBS otimizou os resultados de resistência ao impacto para as blendas ternárias. O módulo de elasticidade dos sistemas diminuiu em relação ao módulo da matriz pura de poliestireno. A granulometria só influenciou de forma significativa na propriedade de resistência ao impacto para as blendas compatibilizadas, sendo a granulometria mais fina a que apresentou melhores resultados. Estes resultados evidenciam uma boa alternativa de tenacificação do poliestireno, bem como reduzir custos utilizando resíduos de borracha que seriam descartados

Palavras-chave: Blendas poliméricas. Tenacificação. Compatibilizante. Granulometria.

\begin{abstract}
One way to modify the properties of polymer systems is to mixture one or more polymer and/or copolymers, i.e., to obtain polymer blends. The aim of this work was to produce polymer blends from a polystyrene matrix with rubber wastes, aiming to study the effect granulometry and compatibilizer on the mechanical properties and impact strength. The blends of polystyrene/rubber wastes were prepared in a corrotacional twin screw extruder and subsequently the extruded granules were injection molded. It was shown that $5 \mathrm{wt} \%$ of the SBS compatibilizer optimized the results of impact strength for ternary blends. The elastic modulus of the systems decreased in relation to modulus of the pure polystyrene matrix. The granulometry influenced significantly the property of impact resistance for the compatibilized blends, with a finer rubber particle size that have the best results. These results show a good alternative for toughening of polystyrene, as well as reduce costs using rubber wastes that would otherwise be discarded.
\end{abstract}

Keywords: Polymer blends. Toughening. Compatibilizer. Granulometry.

\footnotetext{
${ }^{1}$ Aluno PIBIC Engenharia de Materiais, Universidade Federal de Campina Grande; brunobarretodemaufcg@hotmail.com

${ }^{2}$ Doutoranda em Ciência e Engenharia de Materiais pela Universidade Federal de Campina Grande; divaniaf@yahoo.com.br

${ }^{3}$ Aluna PIVIC Engenharia de Materiais, Universidade Federal de Campina Grande; sabrina_materiais@hotmail.com.

${ }^{4}$ Doutora em Engenharia de Materiais pela Universidade Federal de São Carlos. Professora Associada; edcleide@dema.ufcg.edu. br.
} 


\section{Introdução}

A mistura de dois ou mais polímeros (blendas poliméricas) é uma das táticas de desenvolvimento de novos materiais com características diferentes daquelas dos polímeros puros, além de apresentar baixo custo, quando confrontado à síntese de novos polímeros. As blendas poliméricas constituem uma alternativa para a melhoria do desempenho de plásticos de engenharia disponíveis no mercado, pois proporcionam um fator muito importante em relação ao custo/benefício, onde se podem alterar suas propriedades físicas e químicas para uma ampla utilização de materiais poliméricos (BEZERRA et al., 2014).

As propriedades das blendas poliméricas dependem principalmente da miscibilidade entre os dois polímeros. As misturas podem ser heterogêneas ou homogêneas. Nas misturas homogêneas, as propriedades são afetadas pelas interações entre os componentes, enquanto para misturas heterogêneas, o fenômeno interfacial e a natureza flexível ou rígida das fases são importantes (ABREU JÚNIOR; NUNES; VISCONTE, 2010). Entretanto, a maioria das blendas são imiscíveis devido à incompatibilidade química entre os componentes, possuindo elevada tensão interfacial, baixa adesão entre as fases, e apresentando um sistema multifásico (AGRAWAL; ARAÚJO; MÉLO, 2008). Neste caso, é necessário adicionar um agente compatibilizante para melhorar a interação entre as fases e tornar a blenda compatível em seu estado de mistura. Os agentes compatibilizantes geralmente são copolímeros em bloco ou enxertados e podem provocar um decréscimo no tamanho da fase dispersa, melhorar a adesão interfacial, diminuir a tensão superficial e promover a estabilidade morfológica da blenda (LUNA; SILVA; ARAÚJO, 2014; BARRA et al., 2003).

A tenacificação é um dos parâmetros mais importantes que determina se um dado polímero pode ser usado como material de engenharia. Para certas aplicações os polímeros frágeis necessitam ser tenacificados. A principal técnica utilizada pelas indústrias de polímeros tem sido seu reforço com elastômeros. Nas misturas de termoplásticos reforçados com elastômeros, quando se aplica uma tensão, as partículas elastoméricas dispersas concentram ou absorvem essa tensão, provocando uma alteração do estado de tensão da fase matricial, e uma intensa deformação plástica. A absorção-dissipação de energia pelas partículas dispersas se processa por diferentes mecanismos, tais como, cavitação (ruptura), deformação plástica (escoamento), ou por duplo processo de cavitação-deformação (COUTINHO et al., 2007; GUIMARÃES; ROCHA; COUTINHO, 2002; WANG et al., 1998).

Muitos estudos sobre tenacificação de polímeros vêm sendo realizados com o intuito de obter o melhor balanceamento das propriedades. Fang, Guo e Zha (2004) estudaram as propriedades mecânicas como resistência ao impacto de blendas compatibilizadas com SBS. Observou-se que a incorporação de 10\% de SBS a uma blenda PS/EPDM (21\% em peso) aumentou a resistência ao impacto em 20 vezes em relação ao PS. Foi observado redução dos valores de tensão máxima e módulo de elasticidade. As fotomicrografias do MEV e do MET evidenciaram que as blendas de PS/EPDM/SBS com 10\% do compatibilizante. O SBS foi melhor distribuído na interface entre PS e EPDM, independente do conteúdo de EPDM. Não ocorreu alterações significativas nos valores de viscosidade das blendas compatibilizadas e não-compatibilizadas.

Boondamnoen et al. (2012) prepararam blendas de poliestireno com resíduos de borracha natural, bem como borracha vulcanizada nas proporções de $50 / 50 \%$ em peso. O objetivo dos autores era comparar as propriedades de resistência à tração e da morfologia. Além disso, foi determinada a densidade de reticulação utilizando a equação de Flory-Rehner. As blendas foram preparadas em um misturador interno (Haake) na temperatura de $140^{\circ}$ e $60 \mathrm{rpm}$. Os resultados evidenciaram que as blendas de PS/borracha natural apresentaram maior 
resistência à tração e módulo elástico. Porém, a elongação na ruptura foi menor que as blendas com borracha vulcanizada.

Leitzke, Pezzin e Pezzin (2007) estudaram a tenacificação da blenda SAN/NBR. Borrachas de poli(butadieno-co-acrilonitrila) (NBR), com teores de acrilonitrila (NA) variando de 32,9 a 45,7\%, foram incorporadas ao poli(estireno-co-acrilonitrila) (SAN), por extrusão seguida de injeção. A adição do NBR resultou em um aumento significativo na resistência ao impacto e na deformação na ruptura, que foram fortemente influenciados pela composição da blenda, pelo teor de acrilonitrila e pela viscosidade dos NBRs, porém, houve uma diminuição da resistência à tração. Os resultados mais expressivos para resistência ao impacto $(157,1$ $\pm 3,7 \mathrm{~J} / \mathrm{m}$ ) foram obtidos para a blenda 70/30 em peso utilizando NBR com $33,1 \%$ de acrilonitrila e viscosidade Mooney de $51 \mathrm{ML} 1+4\left(100^{\circ} \mathrm{C}\right)$, um valor cerca de $700 \%$ maior que o verificado para o SAN puro $(22,4 \pm 1,1 \mathrm{~J} / \mathrm{m})$. A análise da superfície de fratura por microscopia eletrônica de varredura revelou homogeneidade dos domínios elastoméricos dispersos na matriz, bem como o aparecimento de microtrincas e/ou deformação plástica para todas as blendas. O tamanho dos domínios de NBR diminui com o aumento do teor de acrilonitrila presente no NBR, enquanto a quantidade de domínios diminui com o aumento da viscosidade.

Araújo, Carvalho e Fook (1997) adicionaram resíduos de borracha, provenientes de indústrias de calçados e de pneus ao poliestireno visando tenacificá-lo. As misturas foram realizadas em extrusora dupla-rosca e a moldagem feita por compressão e por injeção. Os efeitos da concentração (5-25\% em peso) e granulometria (1200 a 180mm) dos resíduos nas propriedades mecânicas destas blendas, foram avaliados e as suas superfícies de fratura examinadas. Ficou evidenciado que a resistência à tração tende a diminuir e a resistência ao impacto aumentar conforme o teor de borracha aumenta e a granulometria diminui. A análise morfológica das superfícies de fratura confirma estes resultados. As amostras obtidas pelo processo de injeção apresentaram maior uniformidade e, consequentemente, melhores propriedades mecânicas.

Coutinho et al. (2007) avaliaram a tenacificação de poliestireno (PS) utilizando três tipos de polibutadieno $(\mathrm{PB})$ : polibutadieno baixo-cis $\left(\mathrm{PB}_{\mathrm{b}}\right)$, polibutadieno alto-cis $\left(\mathrm{PB}_{\mathrm{a}}\right)$ e copolímero em bloco (SBS) de estireno e butadieno $\left(\mathrm{PB}_{\mathrm{co}}\right)$. Observaram um aumento na resistência ao impacto de 138, 208 e $823 \%$, quando utilizados polibutadieno baixocis, polibutadieno alto-cis e copolímero em bloco de estireno e butadieno, respectivamente. As condições de processamento tiveram influência na qualidade dos materiais obtidos e temperaturas de processamento superiores a $180^{\circ} \mathrm{C}$ provocaram a degradação do material. As misturas PS/PB exibiram morfologia bifásica com domínios de polibutadieno dispersos aleatoriamente na matriz do PS, com diâmetro de partícula inferior a $1 \mu \mathrm{m}$. Essas misturas apresentaram baixa adesão entre as fases termoplástica e elastomérica e uma alta tensão interfacial. A incorporação de material elastomérico à matriz do PS produziu materiais opacos com alta resistência ao impacto. As misturas $\mathrm{PS} / \mathrm{PB}_{\mathrm{a}}$ apresentaram valores de resistência ao impacto superiores aos das misturas $\mathrm{PS} / \mathrm{PB}_{\mathrm{b}}$ e muito inferiores aos das misturas $\mathrm{PS} / \mathrm{PB}_{\mathrm{co}}$. Observaram que todos os materiais tiveram resistência ao impacto superior ao do HIPS comercial e apresentaram comportamento pseudoplástico, viscoelasticidade e diferentes energias de ativação para o escoamento sob as condições de cisalhamento estudadas.

Martínez-Barrera et al. (2004) investigaram a melhoria nas propriedades de impacto das misturas de poliestireno/SBR produzidas por diferentes concentrações e tipos de estireno-butadieno (SBR). As amostras foram irradiadas por diferentes doses de radiação gama para atingir uma boa aderência e uma boa estabilidade, entre a fase de borracha e a matriz de poliestireno, para melhorias nas propriedades de impacto. Os resultados mostraram que a maior resistência ao impacto foi obtida para a mistura com 
$10 \%$ de SBR, 30\% de estireno, uma conformação linear, uma microestrutura de $53 \%$ de trans, $38 \%$ cis e $9 \%$ de vinil, um peso molecular de 207.000 e uma dose de $100 \mathrm{kGy}$. Várias amostras foram preparadas com $0 \%, 3 \%, 5 \%$ e $10 \%$ de SBR e caracterizadas por FTIR e espectroscopia Raman. Foi possível obter blendas com até $263 \%$ de melhoria nas propriedades de impacto em relação ao PS não modificado. Para amostras irradiadas, um possível mecanismo para explicar o aumento da tenacidade do material é a produção de ligações químicas cruzadas entre o anel benzeno do poliestireno e a matriz de polibutadieno.

O presente trabalho tem como objetivo estudar o efeito do compatibilizante e da granulometria de blendas de PS/SBRr, utilizando um copolímero em bloco como agente de compatibilização (SBS), visando a obtenção de materiais com propriedades mecânicas superiores ou aproximadas ao poliestireno puro.

\section{Materiais e Métodos}

\section{Materiais}

Como matriz polimérica foi utilizado o poliestireno cristal (PS) sob o código 158K Q611 na forma de grânulos, fabricado pela Unigel S.A. Como fase dispersa foi utilizado um composto de borracha reciclada (SBRr), proveniente da indústria de calçados São Paulo Alpargatas S.A. da região de Campina Grande/PB. Como agente compatibilizante foi utilizado o copolímero tribloco linear (SBS), sob o código Kraton D1101B, a base de estireno e butadieno contendo $31 \%$ de poliestireno, na forma de grânulos, adquirido da Activas S.A.

\section{Métodos}

\section{Preparação das blendas}

A blendas binárias PS/SBRr foram preparada na proporção $50 / 50 \%$ em peso e a misturas ternárias
$\mathrm{PS} / \mathrm{SBRr} / \mathrm{SBS}$ nas proporções 47,5/47,5/5\% em peso. A fase dispersa das blendas foi passada em peneira ABNT No $40(0,420 \mathrm{~mm})$ e $\mathrm{N}^{\circ} 18(1 \mathrm{~mm})$.

As blendas foram processadas em uma extrusora dupla rosca corrotacional da Coperion ZSK $18 \mathrm{~mm}$, com temperatura de $190^{\circ} \mathrm{C}$ nas zonas 1 e 2 e $200^{\circ} \mathrm{C}$ nas demais zonas, velocidade de $250 \mathrm{rpm}$ e taxa de alimentação de $4 \mathrm{~kg} / \mathrm{h}$. Os grânulos extrudados foram secos, numa estufa a vácuo com temperatura de $60^{\circ} \mathrm{C}$ durante 48 horas.

Após a secagem, os grânulos extrudados foram moldados por injeção na forma de corpos de prova para ensaios de resistência ao impacto Izod (ASTM D256) e Tração (ASTM D638). Os corpos de prova foram moldados numa temperatura de $180^{\circ}$ na zona 1 e $190^{\circ}$ na zona 2 , tendo um ciclo de injeção de $25 \mathrm{~s}$.

\section{Técnicas de caracterização}

$\mathrm{O}$ ensaio sob impacto Izod foi realizado em corpos de prova entalhados segundo a norma ASTM D256, em um aparelho da marca Ceast modelo Resil 5.5 , operando com martelo de $2,75 \mathrm{~J}$ e os resultados analisados em uma média de 8 corpos de prova.

$O$ teste de resistência à tração uniaxial foi realizado em corpos de prova injetados, segundo a norma ASTM D638, utilizando uma Máquina Universal de Ensaio da Shimadzu, com velocidade de carregamento de $5 \mathrm{~mm} / \mathrm{min}$. Os testes foram conduzidos à temperatura ambiente e os resultados analisados em uma média de 10 corpos de prova.

As análises por microscopia eletrônica de varredura (MEV) foram realizadas na superfície de fratura dos corpos de prova submetidos ao ensaio sob impacto em um microscópio eletrônico de varredura, Shimadzu SSX-550 Superscan, a uma voltagem de $15 \mathrm{kV}$, sob alto vácuo e as superfícies de fratura das amostras entalhadas recobertas com ouro. 


\section{Resultados e Discussão}

\section{Resistência ao impacto}

A resistência ao impacto de termoplásticos é frequentemente aumentada pela incorporação de uma fase elastomérica, isto é, uma fase borrachosa auxilia na tenacificação da matriz. Para a incorporação de resíduos particulados de calçados ou pneus inservíveis em uma matriz polimérica, o tamanho de partícula da borracha e a adesão entre a matriz e a partícula de borracha são considerados os fatores principais no desempenho mecânico das misturas (COSTA et al., 2012). A Figura 1 mostra o comportamento de resistência ao impacto do PS puro, das blendas binárias e ternárias, bem como a tendência destas com as diferentes granulometria e o efeito do compatibilizante.

Conforme a Figura 1 observa-se que o PS apresentou a mais baixa resistência ao impacto em torno de $24 \mathrm{~J} / \mathrm{m}$. O PS puro pode ser caracterizado como um material rígido, porém frágil o que é confirmado pela baixa resistência ao impacto.

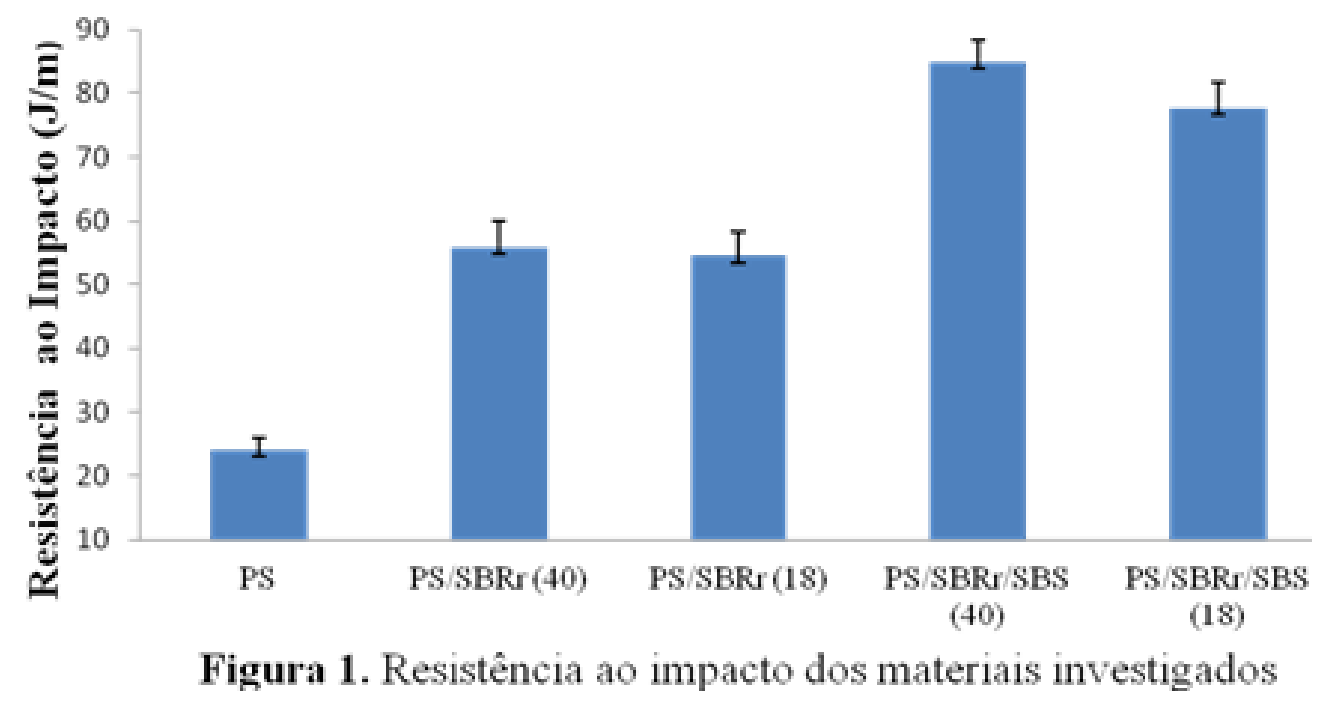

A adição de um material tenaz e flexível (composto de borracha) a uma matriz rígida e amorfa (PS) provoca aumento na tenacidade das blendas e que estas variações são maiores quanto maior for o teor de borracha incorporado (AHMED; JONES, 1990). Observa-se na Figura 1 que independente da granulometria, a resistência ao impacto aumentou substancialmente em relação à matriz pura de PS, e este aumento foi mais pronunciado para as blendas compatibilizadas com $5 \%$ em peso. As blendas binárias $\mathrm{PS} / \mathrm{SBRr}$ passada em peneiras ABNT $40 \mathrm{e}$ 18 aumentaram respectivamente 132,5 e $126,5 \%$ em relação ao PS. Estes aumentos possivelmente pode ser atribuído à capacidade das partículas de borracha, que quando embebidas em polímeros vítreos e submetidas ao campo de tensões associadas a uma trinca que se propaga, de deformarem e cavitarem absorvendo energia de deformação elástica e plástica durante o processo de fratura (ARAÚJO, 1995).

As partículas de borracha quando misturadas com um polímero frágil como o poliestireno, pode induzir o mecanismo de microfibrilamento no material, ocorrendo ao redor do equador das partículas presentes. A vantagem deste mecanismo é que se tem uma distribuição de tensões e, portanto, possibilita-se uma dissipação significativa da energia aplicada antes da geração das trincas. Além disso, o crescimento da fissura é interrompido e reiniciado quando encontra outra partícula de borracha (RABELLO, 2000). Portanto, possivelmente as partículas de borracha atuam como inibidores de crescimento catastrófico das fissuras. 
Visando o aumento da adesão entre as fases foi adicionado às blendas $\mathrm{PS} / \mathrm{SBRr}$ um teor de $5 \%$ do compatibilizante SBS. Um dos efeitos do compatibilizante é reduzir a tensão interfacial entre a fase dispersa e a matriz, ou seja, apresentar um efeito emulsificante, facilitando a dispersão de uma fase na outra. Outro efeito é estabilizar a fase dispersa evitando a sua coalescência (MELO et al., 2000). De acordo com a Figura 1, nota-se que as blendas $\mathrm{PS} / \mathrm{SBR}$ /SBS em ambas as granulometria aumentaram de forma expressiva em relação ao poliestireno puro e as blendas binárias, mostrando assim que são interessantes do ponto de vista tecnológica para aplicações industriais. Então, provavelmente o SBS aumentou a interação destas blendas compatibilizadas, bem como a adesão entre os contornos das fases facilitando a transferência de tensões (ARAYAPRANEE; REMPEL, 2007).

O tamanho das partículas de borracha também é importante, pois interfere diretamente no processo, na estrutura morfológica e nas propriedades da mistura (KATIME; QUINTANA; PRICE, 1995). De acordo com a Figura 1 para as faixas de granulometria investigadas, o tamanho das partículas de borracha passantes na peneira ABNT $\mathrm{N}^{\circ} 40(0,420 \mathrm{~mm})$ apresentaram melhores resultados em relação às partículas passante na peneira ABNT 18 (1 mm), sendo a maior influência para as blendas de PS/ SBRr/SBS. Segundo COSTA (2009) partículas de tamanho maior apresenta resultados interessantes na absorção de impacto, porém tende a reduzir as propriedades mecânicas. Porém, partículas menores promovem uma melhor distribuição das tensões internas e, como consequência um aumento na área superficial das fissuras.

\section{Resistência sob tração}

A Figura 2 apresenta os valores do módulo de elasticidade sob tração das amostras de PS puro, das blendas binárias e ternárias e a tendência destas com as diferentes granulometria.

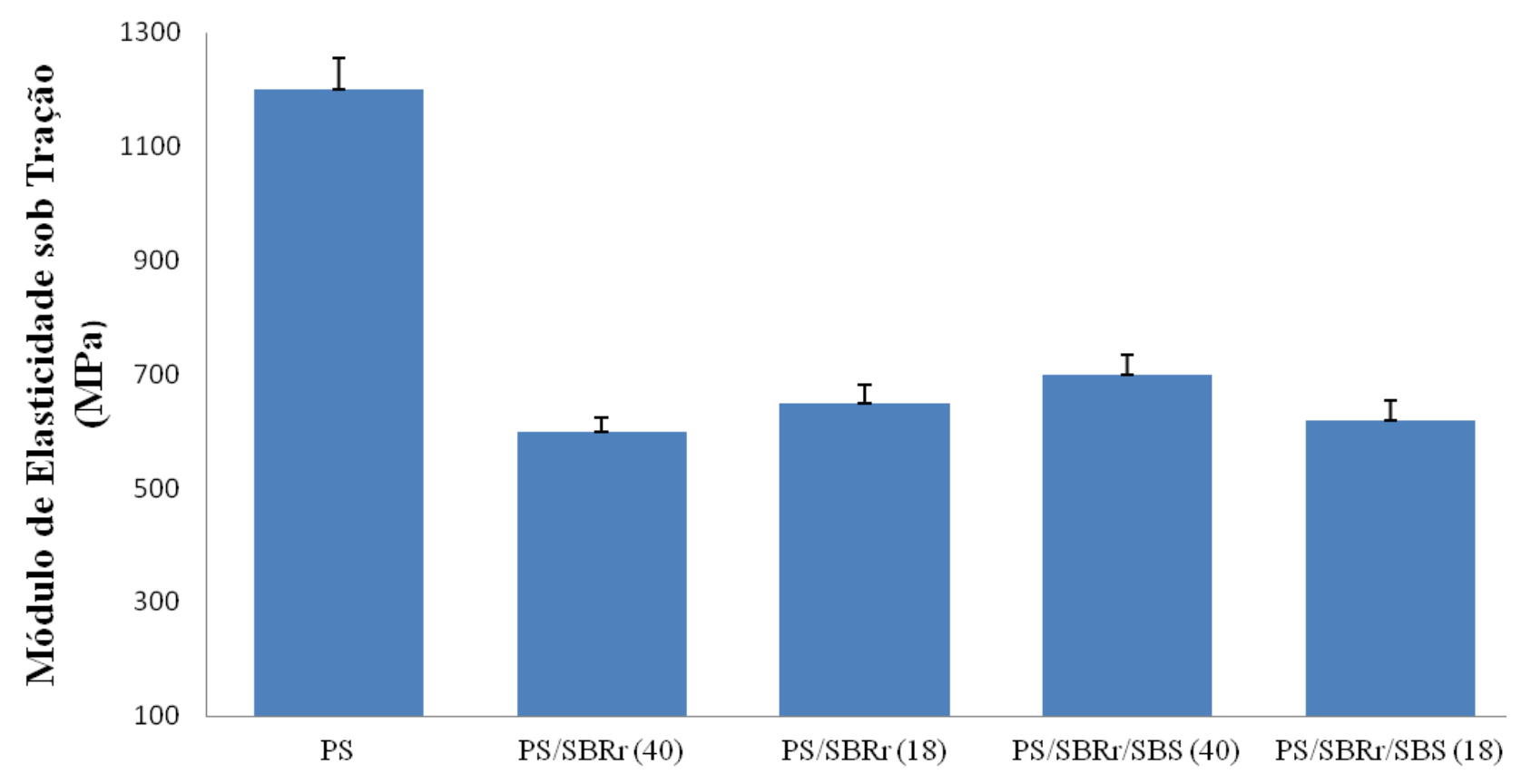

Figura 2. Módulo de elasticidade sob tração dos materiais investigados 
De acordo com a figura 2, o PS apresenta alto módulo de elasticidade. Isto pode ser atribuído à estrutura química do PS que possui anéis aromáticos em sua cadeia lateral que conferem rigidez a este polímero tornando-o um polímero vítreo (VERONESE, 2003).

Conforme a Figura 2 a presença de 50 e 47,5\% de SBRr nas blendas binárias e ternárias respectivamente, alterou drasticamente as propriedades do módulo de elasticidade sob tração em relação a matriz pura de PS. Observa-se que no geral todos os valores de rigidez foram abaixo daqueles obtidos para o PS puro. O módulo de elasticidade das misturas geralmente depende dos valores dos módulos dos componentes. Como os elastômeros possuem baixo módulo, e a temperatura ambiente encontram-se borrachoso, o elevado teor de elastômero na mistura diminui o módulo (ZHANG et al., 2013). Além disso, a presença de microfibrilações implica em um menor módulo elástico (RABELLO, 2000).

Boondamnoen et al. (2012) produziram blendas de PS com resíduos descartados de borracha. Segundo estes autores, a proporção de borracha afeta as propriedades mecânicas das misturas. Eles afirmam que o módulo de elasticidade tende a diminuir quando se aumenta a fração de borracha, uma vez que o aumento de borracha reduz a rigidez da mistura. Portanto, os altos teores em peso de $50 \mathrm{e}$ $47,5 \%$ de borracha incorporada nas blendas de PS/ SBRr e PS/SBRr/SBS, proporcionou o decaimento do módulo das blendas, bem como associado ao fato das partículas de borrachas aumentarem a flexibilidade da cadeia. Entretanto, quando se considera que a incorporação de um material reciclado, com ligações cruzadas em teores de até $50 \%$ em peso no PS, esta redução é aceitável, pois há redução de custo do composto final e aumento da tenacidade do material de forma significativa.

$\mathrm{Na}$ Figura 2, na faixa de granulometria investigada, há pouca influência no módulo de elasticidade das blendas estudadas. Nota-se, que praticamente o fator decisivo para os resultados do módulo de elasticidade possivelmente é o efeito do compatibilizante. Na Figura 2, a blenda PS/SBRr/ SBS (40) foi a que apresentou o melhor resultado do módulo de elasticidade, possivelmente isto pode ser atribuído a ação interfacial do compatibilizante aumentando a adesão entre as fases e tornando o material mais rígido (LIBIO, 2011).

\section{Microscopia Eletrônica de Varredura}

Nas Figuras 3 a 5 estão apresentadas as fotomicrografias obtidas por MEV do PS e das blendas binárias e ternárias com os melhores desempenhos na resistência ao impacto. Estas fotomicrografias foram obtidas da superfície de fratura dos corpos de prova do PS e das blendas binárias e ternárias, submetidas ao ensaio de impacto Izod. As imagens estão com uma ampliação de 1000x.

Figura 3 - Fotomicrografia obtida por MEV do PS puro com uma ampliação de $1000 x$

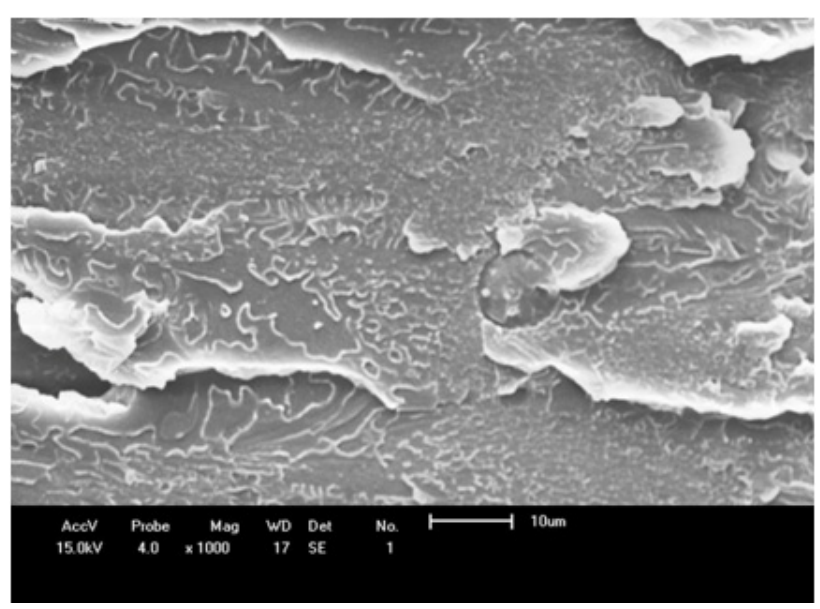


Figura 4 - Fotomicrografia obtida por MEV da blenda PS/SBRr (40) com uma ampliação de 1000x.

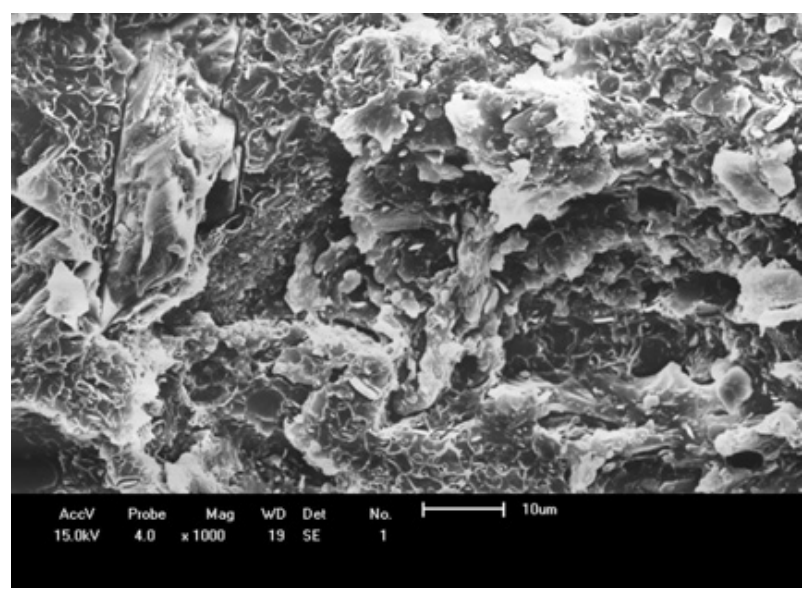

Figura 5 - Fotomicrografia obtida por MEV da blenda PS/SBRr/SBS (40) com uma ampliação de 1000x.

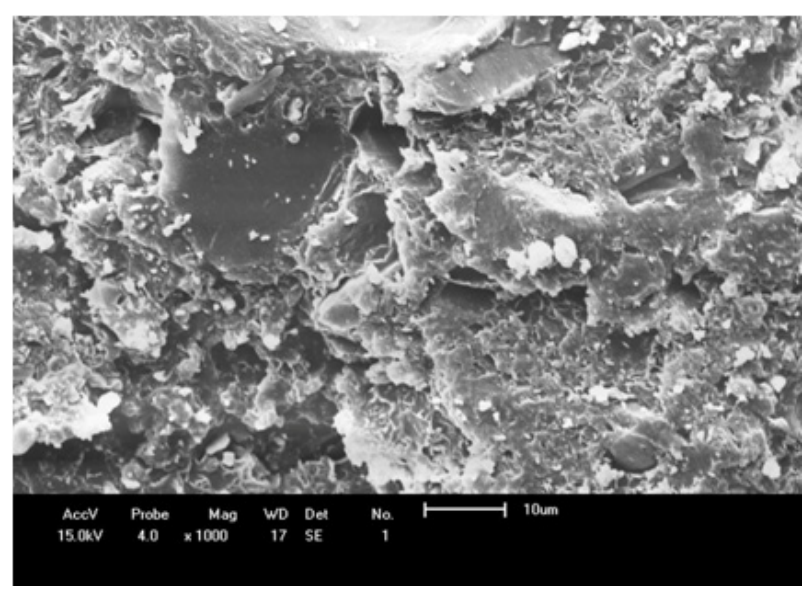

Observam-se nas Figuras 3 a 5 uma grande diferença entre a morfologia do PS puro (Figura 3), que apresenta fratura tipicamente frágil, enquanto nas blendas PS/SBRr 50/50 e PS/SBRr/ SBS 47,5/47,5/5\% são observados locais de alta deformação plástica. Na figura 4 observa-se má adesão entre as fases, provavelmente devido à fraca interação interfacial entre estas, indicando a imiscibilidade do sistema e ainda devido à fraca interação interfacial existem vazios entre os domínios de borracha e da matriz. A presença de vazios na blenda PS/SBRr é resultante do "deslocamento" das partículas de elastômero durante o teste de impacto, as quais haviam sido distribuídas na matriz polimérica durante a mistura mecânica. A morfologia irregular e as superfícies bem definidas dos vazios indicam baixa adesão interfacial entre os dois polímeros, mostrando sua incompatibilidade. Como se pode constatar na Figura 5, a adição do agente compatibilizante à blenda promoveu uma melhor adesão interfacial entre os domínios e a matriz e alterou o tamanho dos domínios em relação às blendas binárias. Este resultado está de acordo com a literatura, uma vez que adicionando o compatibilizante a fase dispersa tende a reduzir o tamanho da partícula. A redução dos tamanhos das partículas dispersas foi provavelmente o fator responsável pelo aumento das propriedades de impacto do material.

\section{Conclusão}

Blendas de PS/resíduo de borracha foram produzidas. A resistência ao impacto tanto para as blendas binárias quanto para as ternárias aumentou expressivamente em relação ao PS puro e este aumento foi maior para as blendas ternárias, indicando o efeito positivo do compatibilizante SBS utilizado. O módulo de elasticidade tende a decair com a incorporação de borracha. A granulometria tem maior influência sobre a resistência ao impacto e praticamente não afeta o módulo de elasticidade para as blendas de PS/SBRr. A blenda ternária PS/SBRr/SBS (40) apresentou a melhor relação de propriedades de tenacidade/rigidez. O resíduo de borracha pode ser reaproveitado no processo de tenacificação de polímeros frágeis, bem como reduzir custo e minimizar os efeitos sobre o meio ambiente. 


\section{Referências}

ABREU JÚNIOR, H. M. B.; NUNES, R. C. R.; VISCONTE, L. L. Y. Misturas NR/SBR: influência da composição e do modo de preparação sobre propriedades mecânicas e reométricas. Polímeros: Ciência e Tecnologia, v. 20, n. 1, p. 1-5, 2010.

AGRAWAL, P.; ARAÚJO, E. M.; MÉLO, T. J. A. Reometria de torque, propriedades mecânicas e morfologia de blendas compatibilizadas de PA6/ PEAD. Polímeros: Ciência e Tecnologia, v. 18, n. 2, p. 152-157, 2008.

AHMED, S.; JONES, F. R. A review of particulate reinforcement theories for polymer composites. Journal of Materials Science, v. 25, n. 12, p. 49334942, 1990.

ARAÚJO, E. M. Aproveitamento de resíduos de borrachas na tenacificação do poliestireno. 1995. Dissertação (Mestrado em Engenharia) Universidade Federal da Paraíba, Campina Grande.

ARAÚJO, E. M.; CARVALHO, L. H.; FOOK, M. V. L. Propriedades mecânicas de blendas PS/ resíduos de borracha-influência da concentração, granulometria e método da moldagem. Polímeros: Ciência e Tecnologia, v. 19, n. 3, p. 45-52, 1997.

ARAYAPRANEE, W.; REMPEL, G. L. Properties of NR/EPDM blends with or without methyl methacrylate-butadiene-styrene (MBS) as a compatibilizer. International Journal of Materials \& Structural Reliability, v. 5, n. 1, p. 1-12, 2007.

BARRA, G. M. O.; ROEDER, J.; SOLDI, V.; PIRES, A. T. N.; AGNELLI, J. A. M. Blendas de poliamida 6/elastômero: propriedades e influência da adição de agente compatibilizante. Polimeros: Ciência e Tecnologia, v. 13, n. 2, p. 94-101, 2003.

BEZERRA, E. B.; LEITE, A. M. D.; ARAÚJO, E. M.; MÉLO, T. J. A. obtenção e caracterização de membranas obtidas a partir de blendas poliméricas de poliamida 6. Polímeros: Ciência e Tecnologia, v. 24, n. 3, p. 381-387, 2014.
BOONDAMNOEN, O.; OHSHIMA, M.; AZURA.; A.R.; CHUAYJULJIT, S.; ARIFFIN, A. Recycling waste natural rubber latex by blending with polystyrene- characterization of mechanical properties. International Journal of Modern Physics: Conference Series, v. 6, p. 391-396, 2012.

COSTA, H. M.; RAMOS, V. D.; SILVA, W. S.; SIRQUIERA, A. S. Otimização de propriedades mecânicas de misturas ternárias de polipropileno (PP)/borracha de etileno-propileno-dieno (EPDM)/ pó de pneus (SRT) sob tração e impacto usando a metodologia da superfície de resposta (MSR). Polímeros: Ciência e Tecnologia, v. 22, n. 1, p. $27-$ 33, 2012.

COSTA, M. P. M. Estudo da tenacificação do poliestireno com elastômeros butadiênicos. 2009. Dissertação (Mestrado em Química) - Universidade do Estado do Rio de Janeiro, Rio de Janeiro.

COUTINHO, F. M. B.; COSTA, M. P. M.; GUIMARÃES, M. J. O. C.; SOARES, B. G. Estudo comparativo de diferentes tipos de polibutadieno na tenacificação de poliestireno. Polímeros: Ciência e Tecnologia, v. 17, n. 4, p. 318-324, 2007.

FANG, Z.; GUO, Z.; ZHA, L. Toughening of Polystyrene with ethylene-propylene-diene terpolymer (EPDM) compatibilized by styrene butadiene block copolymer (SBS) macromolecular. Materials and Engineering, v. 289, n. 8, p.743-748, 2004.

GUimarÃeS, M. J. O. C.; ROCHA, M. C. G.; COUTINHO, F. M. B. Polietileno de alta densidade tenacificado com elastômero metalocênico: 1. propriedades mecânicas e características morfológicas. Polímeros: Ciência e Tecnologia, v. 12, n. 2, p. 76-84, 2002.

KATIME, J.; QUINTANA, J. R.; PRICE, C. Influence os microestrutural on the mechanical properties of high impact polystyrene. Material Letters, v. 22, n. 5-6, p. 297-301, 1995. 
LEITZKE, T. C.; PEZZIN, A. P. T.; PEZZIN, S. H. Blendas SAN/NBR: influência do teor de acrilonitrila e da viscosidade da borracha nitrílica nas propriedades mecânicas. Revista Matéria, v. 12, n. 4 , p. $568-573,2007$.

LIBIO, I. C. Efeito de agentes de compatibilização em blendas de PS/EPDM. 2011. Dissertação (Mestrado de Química) - Universidade Federal do Rio Grande do Sul, Porto Alegre.

LUNA, C. B. B.; SILVA, D. F.; ARAÚJO, E. M. Análise do comportamento termomecânico, térmico e mecânico de blendas de PA6/resíduos de borracha. Revista de Engenharia e Tecnologia, v. 6, n.1, p. 160-169, 2014.

MARTÍNEZ-BARRERA G.; H. LÓPEZ, V. M. CASTAÑO V. M.; RODRÍGUEZ R. Studies on the rubber phase stability in gamma irradiated polystyrene-SBR blends by using FT-IR and raman spectroscopy. Radiation physics and chemistry, v. 69, n. 2, p. 155, 2004.

MELO, T. J. A.; CARVALHO, L. H.; CALUMBY, R. B.; BRITO, K. G. Q.; D’ALMEIDA, J. R. M.; SPIETH, E. Propriedades mecânicas e morfologia de uma blenda polimérica de PP/HIPS compatibilizada com SEBS. Polímeros: Ciência e Tecnologia, v. 10, n. 2, p. 82-89, 2000.

RABELlO, M. S. Aditivação de polímeros. São Paulo: Artliber, 2000. 242 p.

VERONESE, V. B. Desenvolvimento e avaliação de misturas de poliestireno (PS) e copolímero em bloco estireno-butadieno-estireno (SBS). Dissertação (Mestrado em Ciência dos Materiais) Universidade Federal do Rio Grande do Sul, Porto Alegre.

WANG, Z.; CHAN, C. M.; ZHU, S. H.; SHEN, J. Compatibilization of polystyrene and low density polyethylene blends by a two-step crosslinking process. Polymer, v. 39, n. 26, p. 6801-6806, 1998.
ZHANG, J.; CHEN, H.; ZHOU, Y.; KE, C.; LU, H. Compatibility of waste rubber powder/polystyrene blends by the addition of styrene grafted styrene butadiene rubber copolymer: effect on morphology and properties. Polymer Bulletin, v. 70, n. 5, p. 2829-2841, 2013.

\section{Agradecimentos}

Os autores agradecem a São Paulo Alpargatas/ PB pelo fornecimento da matéria prima, a UFCG/ CNPq pela concessão das bolsas e ao $\mathrm{MCTI} / \mathrm{CNPq}$ pelo apoio financeiro.

Recebido em 8 Julho, 2014 - Received on July 8, 2014 Aceito em 22 Julho, 2014 - Accepted on July 22, 2014 